\title{
PENGARUH PENERAPAN STRATEGI PEMBELAJARAN QUICK ON THE DRAW TERHADAP MOTIVASI DAN HASIL BELAJAR SISWA SMP NEGERI 3 PALLANGGA
}

\author{
Nur Ayu Safitri \\ Jurusan Pendidikan Biologi Fakultas Tarbiyah dan Keguruan, \\ UIN AlauddinMakassar, Kampus II J1. H. M. Yasin Limpo Nomor 36 Samata-Gowa, \\ Sulawesi Selatan 92118, Telepon: (0411) 424835, \\ E-mail: nurayusafitri125@gmail.com
}

\author{
Andi Maulana \\ Fakultas Tarbiyah dan Keguruan, \\ UIN AlauddinMakassar, Kampus II J1. H. M. Yasin Limpo Nomor 36 Samata-Gowa, \\ Sulawesi Selatan 92118,Telepon: (0411) 424835, \\ E-mail: maulanaandi.1962@gmail.com

\section{Eka Damayanti} \\ Fakultas Tarbiyah dan Keguruan, \\ UIN AlauddinMakassar, Kampus II J1. H. M. Yasin Limpo Nomor 36 Samata-Gowa, \\ Sulawesi Selatan 92118, Telepon: (0411) 424835, \\ E-mail: eka.damayanti@uin-alauddin.ac.id
}

\begin{abstract}
Abstrak
Tujuan penelitian ini untuk: 1) Mengetahui adanya pengaruh strategi pembelajaran Quick on The Draw terhadap motivasi belajar; 2) Mengetahui adanya pengaruh strategi pembelajaran Quick on The Draw terhadap hasil belajar siswa. Penelitian Quasi Experimental dengan non equivalent control group design ini memiliki sampel masing-masing sebanyak 32 siswa di kelas $\mathrm{VIII}_{4}$ dan kelas VIII $_{5}$ SMP Negeri 3 Pallangga pada materi sistem gerak pada manusia. Instrumen digunakan berupa skala untuk mengetahui motivasi belajar dan tes pilihan ganda untuk mengetahui hasil belajar siswa. Teknik analisis data yang digunakan berupa analisis statistik deskriptif dan statistik inferensial (uji-t) dengan bantuan program SPSS. Hasil analisis data menunjukkan bahwa (1) ada pengaruh strategi pembelajaran Quick on The Draw terhadap motivasi belajar (Independent Sample T-Test $(0,000<0,05))$ yang dibuktikan nilai rata-rata motivasi siswa yang yang diterapkan strategi pembelajaran Quick on The Draw (109) lebih tinggi dibanding siswa yang tidak ada perlakuan (104,12); (2) ada pengaruh strategi pembelajaran Quick on The Draw terhadap hasil belajar siswa pada materi sistem gerak pada manusia kelas VIII SMP Negeri 3 Pallangga (Paired Sample T-Test $(0,000<0,05))$ yang dibuktikan nilai rata-rata hasil belajar siswa setelah
\end{abstract}


diterapkan strategi pembelajaran Quick on The Draw $(73,18)$ lebih tinggi dibanding sebelum perlakuan $(57,07)$.

Kata Kunci: hasil belajar, motivasi belajar, pembelajaran quick on the draw

\begin{abstract}
The purpose of this research was to know the influence of learning quick on the draw strategy to the study motivation and to know the influence of the strategy to student study result. The research was a quasi-experimental with nonequivalent control group design on Human movement systems materials. The sample consisted of 32 students from class of $\mathrm{VIII}_{4}$ and class of VIII $\mathrm{I}_{5}$ of junior high school 3 Pallangga. The instruments used in the research were scale form to know the motivation of the students and multiple choice test to know student study result. The data was analyzed by using descriptive statistics and statistics inferential of t-test of SPSS. Based on the analysis, it showed that there was a significant influence of strategy learning quick on the draw to study motivation with dependent sample ttest score of 0,000 <0,05. The average score of students motivation who applied learning quick on the draw strategy was 109, higher than the students who were not given any treatment 104,12. It also found that there was an influence of the strategy to the student study result of class VIII of junior high schools 3 Pallangga on Human movement systems materials with paired sample t-test of 0,000 < 0,05. The average score of student study result after implementing the strategy was 73,18, higher than before implementing the strategy that was only 57,07.
\end{abstract}

Key words: study results, motivation, learning quick on the draw strategy

\title{
PENDAHULUAN
}

Tema pendidikan tidak pernah basi diangkat dalam penelitian khususnya dalam penelitian aplikatif di sekolah. Pendidikan yang berisi interaksi antara pendidik dengan siswa. Interaksi yang dimaksud yaitu saling mempengaruhi antara pendidik dengan siswa. Dimana guru bertugas untuk menumbuhkembangkan potensi siswa dengan cara membimbing siswa. Dinamika yang terjadi dalam interaksi tersebut sangat banyak dan menjadi bahan yang tidak habis dijadikan kajian dalam penelitian.

Pendidikan sangat penting karena merupakan prioritas utama sebagai upaya pemerintah dalam mencerdaskan kehidupan bangsa. Tanpa terpenuhinya aspek pendidikan dalam kehidupan sosial kemasyarakatan akan berdampak pada minimnya sumber daya manusia. Para ahli memberikan definisi tentang pendidikan secara berbeda-beda, namun tetap pada substansi yang sama. Menurut Azyumardi Azra sebagaimana yang di kutip dalam buku Muslich (2011: 48) menyatakan bahwa 
pendidikan adalah salah satu proses untuk mempersiapkan generasi muda untuk memenuhi tujuan hidup secara efektif dan efisien.

Guru sebagai pendidik memegang peranan penting dalam menumbuhkembangkan potensi yang dimiliki oleh setiap siswa secara optimal dalam mendapatkan hasil belajar yang tinggi sesuai yang diharapkan. Oleh sebab itu, peningkatan mutu seorang guru sangatlah penting karena peran guru yang begitu besar yakni untuk mencetak siswa yang berkualitas tinggi sehingga hasilnya sesuai dengan tujuan yang diharapkan.

Didalam melaksanakan pembelajaran, salah satu unsur penting dari seorang guru adalah kreativitas dalam memilih strategi yang akan digunakan. Strategi yang tepat dapat menjadikan siswa termotivasi selama proses pembelajaran berlangsung dan akhirnya mendapatkan hasil belajar yang maksimal karena motivasi dapat menumbuhkan minat belajar seseorang.

Fathurrohman dan Sobry (2007: 19) menyebutkan motivasi adalah keseluruhan daya penggerak didalam diri seseorang yang menimbulkan, menjamin kelangsungan dan memberikan arah kegiatan belajar sehingga diharapkan tujuan yang dapat tercapai. Motivasi berfungsi sebagai pendorong, pengarah, dan sekaligus sebagai penggerak perilaku seseorang untuk mencapai suatu tujuan. Disinilah guru berperan penting melakukan strategi yang tepat agar siswa dapat termotivasi dalam belajar.

Motivasi belajar berhubungan erat dengan hasil belajar. Hasil penelitian Latif, dkk (2017: 192) menunjukkan bahwa tingginya hasil belajar siswa disebabkan karena penerapan teknik reinforcemen yang dapat membangkitkan motivasi atau dorongan kepada siswa untuk lebih giat melakukan sesuatu yang positif dalam proses belajar mengajar.

Jihad dan Haris (2012: 19) mengungkapkan bahwa adapun cara untuk memperoleh hasil belajar siswa, yaitu dengan melihat aspek pengetahuan yang dimiliki siswa dengan cara diadakannya evaluasi atau tes akhir untuk mengetahui tingkat penguasaan siswa. Selain aspek pengetahuan, sikap dan kerampilan yang dimiliki oleh siswa juga menjadi acuan dalam penilaian hasil belajar siswa.

Setiap siswa memiliki motivasi dan hasil belajar yang berbeda-beda. Ada siswa yang memiliki motivasi dan hasil belajar yang tinggi dan ada siswa yang memiliki motivasi dan hasil belajar yang rendah. siswa yang memiliki motivasi dan hasil belajar yang tinggi ialah siswa yang mempunyai kesadaran dalam belajar. Sedangkan siswa yang memiliki motivasi dan hasil belajar rendah atau tidak mempunyai motivasi sama sekali adalah siswa yang belum sadar akan pentingnya belajar. Oleh sebab itu, guru berperan penting dalam memotivasi anak didiknya sehingga dapat menghasilkan hasil belajar yang tinggi yaitu dengan menggunakan strategi pembelajaran yang tidak monoton dan melibatkan siswa secara aktif dalam proses pembelajaran.

Berdasarkan hasil wawancara di SMP Negeri 3 Pallangga di awal bulan Juni 2017 dengan K salah satu guru IPA, manyatakan bahwa masih banyak siswa yang kurang termotivasi dalam belajarnya, terlihat dari kurangnya siswa yang aktif, masih banyak yang kurang memperhatikan pembelajaran yang sedang berlangsung, kurang 
bersemangat dan merasa bosan dalam belajarnya. Sedangkan hasil wawancara dari beberapa siswa mengatakan bahwa setiap guru yang masuk mengajar kebanyakan guru menggunakan metode konvensial. Ada juga guru yang hanya memerintahkan untuk menyalin terus menerus sehingga siswa cepat merasa bosan dan kurang bergairah atau tidak tartarik selama proses pembelajaran berlangsung. Dari pernyataan tersebut kurangnya minat belajar siswa dapat berpengaruh terhadap hasil belajar siswa karena dalam proses pembelajaran.

Dimyati dan Mudjiono (2002: 55) mengungkapkan bahwa keberhasilan siswa dipengaruhi oleh faktor internal dan eksternal. Dimana faktor eksternal tersebut adalah motivasi siswa itu sendiri. Sedangkan faktor eksternal yang sangat penting adalah guru, dimana guru harus berusaha dan lebih terampil dalam menggunakan berbagai strategi pembelajaran untuk tercapainya tujuan pembelajaran dikelas termasuk didalamnya strategi pembelajaran yang digunakan oleh guru. Adapun solusi yang dilakukan untuk mengatasi pembelajaran yang membosankan agar siswa ikut termotivasi serta aktif dalam proses belajar yaitu dengan menggunakan penerapan strategi pembelajaran Quick on The Draw.

Ginnis (2009: 163) menyatakan bahwa strategi pembelajaran Quick on The Draw merupakan suatu strategi yang dalam penerapannya mengajak siswa untuk bermain sambil belajar, sehingga kejenuhan dalam belajar dapat diatasi. Strategi Pembelajaran Quick On The Draw dapat mendorong aktivitas kerja sama kelompok dalam suasana permainan, memberi pengalaman dalam keterampilan membaca, siswa dapat belajar mandiri dan kecepatan dan ketepatan dalam menjawab pertanyaan sehingga siswa dapat menyadari bahwa pembagian tugas lebih produktif daripada menduplikasi tugas. Strategi Pembelajaran Quick On The Draw memberikan pengalaman mengenai keterampilan membaca yang didorong oleh kecepatan aktivitas, ditambah belajar mandiri dan kecakapan ujian yang lain. Kegiatan ini membantu siswa untuk membiasakan diri mendasarkan belajar pada sumber bukan guru. Dalam pembelajaran dengan penerapan strategi Pembelajaran Quick On The Draw, dapat memperhatikan kerja sama, sehingga dapat menciptakan hubungan sosial antara siswa dengan siswa lainnya dan pembelajaran secara kooperatif dengan sendirinya tercipta tapi tetap memfokuskan pada pribadi siswa agar dapat memperoleh standar yang tinggi. Penilaian yang dilakukan tidak hanya melihat pada satu sisi, selain hasil proses pembelajaran juga berperan dalam penilaian terhadap siswa dengan demikian dapat membantu siswa untuk tumbuh dan berkembang.

Lestiyaningsih., dkk (2013: 4) dalam penelitiannya menemukan bahwa strategi pembelajaran Quick on The Draw dapat meningkatkan hasil belajar siswa. Dalam penelitian tersebut menunjukkan Quick on The Draw dapat meningkatkan hasil belajar siswa dari siklus pertama dan siklus ke dua serta dapat dilihat dari presentase ketuntasan hasil belajar pada siklus I mencapai 82,85\% sedangkan pada siklus II 97,14\%.

Strategi pembelajaran Quick on The Draw pada dasarnya cocok dengan semua materi biologi kerena konsepnya hanya mengarah pada kecepatan dan ketetapan saja dalam menjawab pertanyaan-pertanyaan dari materi yang sedang diajarkan Ginnis 
(2009: 163). Dengan demikian, maka menarik menjadikan tema penelitian "Pengaruh Penerapan Strategi Pembelajaran Quick on The Draw Terhadap Motivasi dan Hasil Belajar Siswa Kelas VIII SMP Negeri 3 Pallangga pada Materi Sistem Gerak Pada Manusia". Rumusan pertanyaan yang dijawab dalam penelitian ini: (1) adakah pengaruh strategi pembelajaran Quick on The Draw terhadap motivasi belajar siswa kelas VIII SMP Negeri 3 Pallangga pada materi sistem gerak manusia?; (2) adakah pengaruh strategi pembelajaran Quick on The Draw terhadap hasil belajar siswa kelas VIII SMP Negeri 3 Pallangga pada materi sistem gerak manusia?

Adapun tujuan penelitian penelitian ini untuk: (1) Mengetahui adanya pengaruh strategi pembelajaran Quick on The Draw terhadap motivasi belajar siswa kelas VIII SMP Negeri 3 Pallangga pada materi sistem gerak pada manusia; (2) Mengetahui adanya pengaruh strategi pembelajaran Quick on The Draw terhadap hasil belajar siswa kelas VIII SMP Negeri 3 Pallangga pada materi sistem gerak pada manusia.

Manfaat yang dapat diperoleh setelah melakukan penelitian ini adalah bagi pendidik, dapat digunakan sebagai alternatif pilihan strategi pembelajaran terutama yang berorientasi atau yang mengacu pada hasil belajar siswa. Bagi siswa, diharapkan dapat mengembangkan aktifitas dan kreatifitas berfikir untuk meningkatkan hasil belajarnya. Bagi peneliti, peneliti ini sifatnya sebagai bahan perbandingan dan referensi bagi para peneliti selanjutnya.

\section{METODOLOGI PENELITIAN}

Penelitian ini merupakan jenis penelitian eksperimen dengan bentuk quasi eksperimen design atau eksperimen semu dengan menggunakan desain penelitian nonequivalent control group design. Penelitian ini dilaksanakan di SMP Negeri 3 Pallangga letaknya di jalan Benteng Somba Opu No. 221, Jenetallasa, Pallangga Kabupaten Gowa, dengan mata pelajaran sistem gerak pada manusia. Subjek penelitian adalah siswa kelas VIII SMP Negeri 3 Pallangga. Populasi penelitian ini yaitu seluruh siswa kelas VIII SMP Negeri 3 Pallangga. Sampel penelitian ini adalah siswa kelas $\mathrm{VIII}_{4}$ sebagai kelas kontrol dan kelas $\mathrm{VIII}_{5}$ sebagai kelas eksperimen.

Penelitian ini dilaksanakan dalam lima tahap meliputi tahap perencanaan, persiapan, pelakasanaan, pengolahan data, dan pelaporan. Data-data pada penelitian ini diperoleh dengan menggunakan instrument angket motivasi belajar siswa sebanyak 42 item pertanyaan dan tes hasil belajar dalam bentuk pilihan ganda sebanyak 30 butir soal.

Data hasil pada penelitian ini diolah dengan teknik analisis data statistik deskriptif dan analisis data inferensial. Sugiyono (2016: 52) mengungkapkan bahwa analisis data deskriptif dilakukan untuk menentukan nilai rata-rata (mean), menghitung standar deviasi, dan variansi sampel. Selanjut dilakukan analisis statistik inferensial. Dalam analisis statistik inferensial dilakukan tiga pengujian yaitu uji normalitas untuk mengetahui distribusi data normal atau tidak, uji homogenitas untuk mengetahui variansi sampel homogeni atau tidak, dan uji hipotesis. 
Uji normalitas dilakukan dengan menggunakan uji One Sample KolmogorovSmirnov Test. Kriteria penentuan normalitas data dengan melihat nilai Asymp. Sig. (2tailed), jika nilai Asymp. Sig. (2-tailed)>0,05 maka populasi berdistribusi normal dan jika nilai Asymp. Sig. (2-tailed) $<0,05$ maka populasi tidak berdistribusi normal (Priyatno, 2010: 99). Selanjutnya Priyatno mengungkapkan bahwa uji homogenitas dilakukan menggunakan SPSS versi 16.0 for Windows dengan uji Levene statistic. Populasi dikatakan homogenjika sig.> 0,05 dan jika sig. $<0.05$ maka data populasi tersebut tidak homogen.

Uji hipotesis dilakukan dengan menggunakan analisis Independent Samples Test untuk motivasi belajar dan Paired sample Test untuk hasil belajar. Jika nilai sig. (2tailed) $<0,05$ maka terdapat pengaruh penerapan pengaruh yang signifikan antara strategi pembelajaran Quick on The Draw terhadap motivasi belajar dan hasil belajar siswa kelas VIII SMP Negeri 3 Pallangga pada materi sistem gerak pada manusia. Jika nilai sig. (2-tailed)>0,05 maka tidak terdapat pengaruh antara strategi pembelajaran Quick on The Draw terhadap motivasi belajar dan hasil belajar siswa kelas VIII SMP Negeri 3 Pallangga. (Sugiyono, 2015).

\section{HASIL PENELITIAN DAN PEMBAHASAN}

Data hasil penelitian yang didapatkan dari siswa SMP Negeri 3 Palllangga pada siswa kelas VIII dengan menggunakan strategi pembelajaran Quick on The Draw, yang peneliti kumpulkan melalui instrument angket untuk mengukur motivasi belajar siswa dan tes dari nilai hasil belajar pretest dan posttest siswa. Data tersebut dianalisis menggunakan statistik inferensial dan statistik deskriptif. Pengujian hipotesis digunakan uji-t dengan taraf signifikansi $\alpha=0,05$. Syarat yang harus dipenuhi untuk pengujian hipotesis adalah data yang diperoleh berdistribusi normal dan mempunyai variansi yang homogen. Oleh karena itu sebelum melakukan pengujian hipotesis uji statistic inferensial, terlebih dahulu dilakukan uji prasyarat analisis dengan uji normalitas dan uji homogenitas.

Tabel 1: Hasil Uji Normalitas

\begin{tabular}{llll}
\hline Variabel & K-SZ & Sig & Keterangan \\
\hline Motivasi belajar eksperimen & 0,836 & 0,487 & Normal \\
Motivasi belajar control & 1,075 & 0,198 & Normal \\
Hasil belajar pretest eksperimen & 1,058 & 0,213 & Normal \\
Hasil belajar pretest control & 0,670 & 0,760 & Normal \\
Hasil belajar posttes eksperimen & 0,827 & 0,501 & Normal \\
Hasil belajar posttes control & 0,735 & 0,652 & Normal \\
\hline
\end{tabular}


Berdasarkan uji normalitas dengan menggunakan uji Kolmogorov-Smirnov di atas, diperoleh nilai KSZ untuk kelas eksperimen pada variabel motivasi belajar siswa sebesar 0,836, dan untuk variabel hasil belajar pada pretest sebesar 1,058 dan pada posttes sebesar 0,827 sedangkan untuk kelas kontrol variabel motivasi belajar siswa sebesar 0,075 dan untuk variabel hasil belajar pada pretest sebesar 0,670 dan pada posttes sebesar 0,735. Nilai Asymp.Sig. (2-tailed) untuk kelas eksperimen variabel motivasi belajar siswa sebesar 0,760, dan untuk variabel hasil belajar pada pretest sebesar 0,760 dan pada posttes sebesar 0,501 sedangkan untuk kelas kontrol pada variabel motivasi belajar siswa sebesar 0,198 dan untuk variabel hasil belajar pada pretest sebesar 0,760 dan pada posttes sebesar 0,652. Hasil yang diperoleh lebih besar dari $0,05(>0,05)$ maka dapat disimpulkan data terdistribusi normal.

Kemudian dilakukan uji homogenitas dengan menggunakan uji Levene untuk melihat apakah data yang diperoleh pada penelitian ini memiliki variansi yang sama (homogen) atau tidak. Adapun hasil uji homogenitas data motivasi belajar siswa diperoleh nilai sig.hitung $=0,119$, hal ini menunjukkan sig.hitung $>0,05$ dan uji homogenitas data hasil belajar siswa diperoleh nilai sig.hitung $=0,111$ hal ini menunjukkan sig.hitung > 0,05 maka dapat disimpulkan bahwa data tersebut berasal dari populasi yang homogen.

\section{Pengaruh Strategi Pembelajaran Quick on The Draw terhadap Motivasi Belajar Siswa}

Berdasarkan hasil pengujian hipotesis menggunakan independent sample $T$ test dengan bantuan SPSS yang memperlihatkan bahwa nilai $\mathrm{p}=0,000(\mathrm{p}<0,05)$ artinya ada perbedaan antara motivasi belajar antara siswa yang diajar dengan menggunakan strategi Quick on The Draw dengan tanpa menggunakan strategi Quick on The Draw. Hasil statistic inferensial tersebut didukung dengan statistik deskriptif seperti di bawah ini:

Tabel 2. Hasil Analisis Deskriptif Motivasi Belajar

\begin{tabular}{lcc}
\hline Statistik & Kelas Kontrol & Kelas Eksperimen \\
\hline Sampel & 32 & 32 \\
Skor terendah & 96,00 & 98,00 \\
Skor tertinggi & 113,00 & 120,00 \\
Rata-rata & 104,12 & 109 \\
Standar Deviasi & 4,86 & 7,16 \\
\hline
\end{tabular}


Hasil analisis deskriptif di atas menunjukkan pada kelas eksperimen nilai ratarata pada motivasi belajar siswa tanpa diajar dengan menggunakan strategi Quick on The Draw adalah 104,12 dengan standar deviasi 4,86 dengan nilai terendah 96,00 dan niilai tertingi 113,00 . Sedangkan nilai rata-rata motivasi belajar siswa di kelas eksperimen yang mendapatkan perlakuan diajar menggunakan strategi Quick on The Draw adalah diperoleh nilai rata-rata 109 dengan standar deviasi 7,16 dengan nilai terendah 98,00 dan nilai tertinggi 120,00. Hal tersebut menunjukkan lebih tingginya nilai motivasi belajar siswa yang di ajar menggunakan strategi Quick on The Draw dibanding siswa tanpa diajar menggunakan strategi Quick on The Draw. Artinya ada pengaruh strategi pembelajaran quick on the draw terhadap motivasi belajar siswa kelas VIII SMP Negeri 3 Pallangga pada materi system gerak pada manusia.

Hal itu sejalan dengan pengamatan peneliti yang tampak di dalam kelas eksperimen. Ketika proses pembelajaran berlangsung, siswa sangat antusias untuk berpartisipasi selama kegiatan pembelajaran berlangsung. Siswa tampak terlibat aktif dan antusias selama pembelajaran berlangsung dimana strategi yang digunakan mengajak siswa untuk berlomba dalam menjawab pertanyaan. Keadaan berbeda jika dilihat pada kelas kontrol yang mana pembelajaran dilakukan dengan diskusi pada umumnya. Siswa di kelas kontrol tampak kurang antusias dalam pembelajaran. Siswa yang mengerjakan tugas dengan sungguh-sungguh hanyalah kelompok yang didalam anggotanya terdapat siswa yang pandai dan tidak semua siswa aktif di dalam proses pembelajaran.

Hal tersebut sejalan dengan pendapat Ginnis (2009) yang menyatakan bahwa menyatakan bahwa strategi pembelajaran Quick on The Draw ini mampu mendorong siswa untuk bermain sambil belajar, sehingga kejenuhan dalam belajar dapat diatasi. Hal itu terjadi karena strategi pembelajaran Quick On The Draw ini dapat mendorong aktivitas kerja sama kelompok dalam suasana permainan, memberi pengalaman dalam keterampilan membaca, siswa dapat belajar mandiri dan kecepatan dan ketepatan dalam menjawab pertanyaan sehingga siswa dapat menyadari bahwa pembagian tugas lebih produktif daripada menduplikasi tugas. Selain itu strategi ini mampu meningkatkan kemandirian dan kecakapan dalam menjawab soal ujian.

\section{Pengaruh Strategi Pembelajaran Quick on The Draw terhadap Hasil Belajar Siswa}

Berdasarkan hasil pengujian hipotesis menggunakan Paired Sample T test dengan bantuan SPSS yang memperlihatkan bahwa nilai $\mathrm{p}=0,000(\mathrm{p}<0,05)$ artinya ada perbedaan antara hasil belajar siswa sebelum diterapkan pembelajaran menggunakan strategi Quick on The Draw dengan setelah diterapkan pembelajaran menggunakan strategi Quick on The Draw. Hasil statistic inferensial tersebut didukung dengan statistik deskriptif seperti di bawah ini: 
Tabel 3. Hasil Analisis Deskriptif Hasil Belajar Kelas Eksperimen

\begin{tabular}{llc}
\hline Statistik & Sebelum Perlakuan & Setelah Perlakuan \\
\hline Sampel & 32 & 32 \\
Skor terendah & 20,00 & 47,00 \\
Skor tertinggi & 60,00 & 87,00 \\
Rata-rata & 34,40 & 73,18 \\
Standar Deviasi & 11,61 & 9,54 \\
\hline
\end{tabular}

Berdasarkan pada tabel di atas, untuk pretest atau sebelum perlakuan, nilai hasil belajar terendah 20,00 dan tertinggi 60,00 serta standar deviasi 11,61 dengan rerata sebesar 34,40. Sementara untuk posttest atau setelah perlakuan, nilai hasil belajar terendah 47,00 dan tertinggi 87,00 serta standar deviasi 9,54 dengan rerata sebesar 73,18. Hasil tersebut menunjukkan adanya peningkatan hasil belajar siswa setelah diajar menggunakan strategi pembelajaran Quick on The Draw. Artinya ada pengaruh strategi pembelajaran quick on the draw terhadap hasil belajar siswa kelas VIII SMP Negeri 3 Pallangga pada materi system gerak pada manusia.

Hasil penelitian ini juga sejalan dengan hasil penelitian dari Lestiyaningsih., dkk (2013: 4) bahwa strategi pembelajaran Quick on The Draw dapat meningkatkan hasil belajar siswa. Begitu pula sejalan dengan penelitian dari Ahmad Ali (2010) yang berjudul "pengaruh strategi Quick on The Draw terhadap penguasaan siswa pada konsep sel di kelas XI IPA SMA Negeri 1 Tellulimpoe Kab. Sinjai”. Hal ini ditunjukkan pada hasil penelitian ini yang menunjukkan adanya perbedaan yang signifikan hasil belajar biologi antara kelompok yang diajar dengan menggunakan strategi pembelajaran Quick On The Draw dengan kelompok yang diajarkan dengan pembelajaran konvensional.

Berdasarkan uraian di atas, dapat disimpulkan bahwa strategi pembelajaran Quick on The Draw berpengaruh terhadap peningkatan motivasi belajar dan hasil belajar siswa pada mata pelajaran sistem gerak pada manusia.

\section{KESIMPULAN}

Hasil penelitian ini dapat disimpulkan bahwa (1) Hasil Independent Sample T-Test $(0,000<0,05)$ menunjukkan adanya perbedaan antara motivasi belajar siswa yang diterapkan strategi pembelajaran Quick on The Draw dengan siswa yang tidak ada perlakuan. Karena nilai rata-rata motivasi siswa yang yang diterapkan strategi pembelajaran Quick on The Draw (109) lebih tinggi dibanding siswa yang tidak ada perlakuan (104,12), maka disimpulkan ada pengaruh strategi pembelajaran Quick on The Draw terhadap motivasi belajar; (2) Hasil Paired Sample T-Test $(0,000<0,05)$ menunjukkan adanya perbedaan antara hasil belajar siswa sebelum dan sesudah 
diterapkan strategi pembelajaran Quick on The Draw. Karena nilai rata-rata hasil belajar siswa setelah diterapkan strategi pembelajaran Quick on The Draw $(73,18)$ lebih tinggi dibanding sebelum perlakuan (57,07), maka disimpulkan bahwa ada pengaruh strategi pembelajaran Quick on The Draw terhadap hasil belajar siswa pada materi sistem gerak pada manusia kelas VIII SMP Negeri 3 Pallangga.

\section{DAFTAR PUSTAKA}

Ali, Ahmad. (2013). Pengaruh Strategi Quick on The Draw Terhadap Penguasaan Siswa Pada Konsep Sel di Kelas XI IPA SMA Negeri 1 Tellulimpoe Kab. Sinjai, Jurnal Biotek (Online), Vol 1 No 1 . (http://journal.uinalauddin.ac.id/index.php/biotek/article/view/1041, diakses 11 November 2017)

Dimyati dan Mudjiono. (2012). Belajar dan Pembelajaran. Cet. II; Jakarta: Rineka Cipta.

Fathurrohman, Pupuh, \& Sobry, M. Satikno. (2007). Strategi Belajar Mengajar. Bandung: PT Refika Aditama.

Ginnis, Paul. (2009). Trik dan Taktik Mengajar. Akarta: PT. Indeks.

Jihad, Asep., \& Haris, Abdul. (2012). Evaluasi Pembelajaran. Cet I Yogyakarta: Multi Pressindo.

Latif, Andi Makkawari., Muchlisah., \& Damayanti, Eka. (2017). Pengaruh teknik reinforcement terhadap hasil belajar biologi pokok bahasan sistem peredaran darah manusia. Jurnal Biotek (Online), Vol 5 No 1 (http://journal.uinalauddin.ac.id/index.php/biotek/article/view/3457, diakses 15 November 2017)

Lestiyaningsih, Herdika., Hobri, H., \& Kristiani, Arika Indah. (2013). Penerapan Pembelajaran Quick on The Draw Untuk Meningkatkan Hasil Belajar Matematika Pada Sub Pokok Bahasan Aritemetika Sosial. Kadikma (Online), Vol. 4, No.2. (http://jurnal.unej.ac.id/index.php/kadikma/article/view/1037, diakses 1 Agustus 2017)

Muslich, Masnur. (2011). Pendidikan Karakter: Menjawab Tantangan Krisis Multidimensional. Cet. I; Jakarta: PT. Bumi Aksara.

Priyatno, Duwi, (2010). Teknik Muda Dan Cepat Melakukan Analisis Data Penelitian Dengan SPSS. Yogyakarta: Mediakom.

Sugiyono, (2016). Metode Penelitian Kuantitatif dan R\&D.Cet. 23; Bandung: Alfabeta. Sugiyono, (2015). Metode Penelitian Pendidikan. Bandung: Alfabeta. 